\title{
O BAZAR CORUMBAENSE - ANÁLISE DAS RELAÇÕES SOCIAIS QUE SE ESTABELECEM A PARTIR DO COMÉRCIO DE DROGAS ILEGAIS NA CIDADE DE CORUMBÁ FRONTEIRA COM A BOLÍVIA
}

\author{
THE CORUMBAENSE BAZAR - ANALYSIS OF THE SOCIAL \\ RELATIONS THAT ARE ESTABLISHED FROM THE TRADE OF \\ ILLEGAL DRUGS IN THE CITY OF CORUMBÁ BORDER WITH \\ BOLIVIA
}

Giovanni França Oliveira ${ }^{1}$

\begin{abstract}
RESUMO: A fronteira da conurbação de Corumbá-Ladário/Brasil - Puerto Quijarro/Puerto Suarez/Bolívia configura-se atualmente, segundo a Secretaria Nacional de Segurança Pública (SENASP) do Brasil, como umas das três principais portas de entradas de drogas ilícitas provindas da Bolívia, Peru e Colômbia. Este artigo tem como objetivo demonstrar a formação, a estruturação do comércio de drogas ilícitas no varejo na cidade de Corumbá, a partir do trabalho etnográfico realizado entre os anos de 2010- 2014.
\end{abstract}

PALAVRAS-CHAVE: Corumbá, Fronteira, Tráfico de drogas, Bocas de Fumo, Primeiro Comando da Capital (PCC).

ABSTRACT: The border of the conurbation of Corumbá - Ladário / Brazil -Puerto Quijarro / Puerto Suarez/ Bolivia is currently configured, according to the National Secretariat of Public Security ( SENASP ) of Brazil, as one of the three main ports of illicit drugs coming from Bolivia, Peru and Colombia. This article hás to demonstrate the formation, structuring the trade in illicit drugs at retail in the city of Corumbá, from the ethnographic work conducted between 2010-2014.

KEYWORDS: Corumbá; Border; Drug Trafficking; Smokehooks; First Command of the Capital (PCC).

\footnotetext{
*Pesquisa decorrente da dissertação de mestrado intitulada "Nas bocas da cidade de Corumbá: o comércio de drogas na fronteira Brasil/Bolívia", desenvolvido na Universidade Federal de Mato Grosso do Sul/Campos do Pantanal, com financiamento da CAPES.

${ }^{1}$ Possui graduação em História pela Universidade Federal de Mato Grosso do Sul (2010), mestre em Estudos Fronteiriços pela UFMS(2013). Pesquisador Grupo de Estudos e Pesquisas sobre Ensino de História (GEPEH-UFMS), Pesquisador do Observatório da Violência e Sistema Prisional- UFMS. atualmente é doutorando em História pela Universidade Federal da Grande Dourados (UFGD). Atua principalmente nos seguintes temas: Ensino de História, História Regional, violência e Fronteiras.
} 
RESUMEN: La frontera del Conurbano Corumbá - Ladário / Brasil - Puerto Quijarro Puerto Suárez / Bolivia se configura actualmente, según la Secretaría Nacional de Seguridad Pública (SENASP) en Brasil, como uno de los tres principales puertos de entrada de drogas ilícitas de Bolivia, Perú y Colombia. Este artículo tiene como objetivo demostrar la formación y la estructuración del comercio minorista de drogas ilícitas en la ciudad de Corumbá, a partir del trabajo etnográfico realizado entre los años 2010-2014.

PALAVRAS-CHAVE:Corumbá, Fronteira, Narcotráfico, Bocas de Fumo, Primer Comando de la Capital (PCC).

\section{Introdução}

As articulações e estratégias presentes no ramo empresarial do tráfico de drogas, cada vez mais deixam de ser problema das grandes metrópoles brasileiras, se alastrando para todo o território brasileiro. Com isso, as fronteiras brasileiras atualmente vêm ganhando maior atenção não apenas em decorrência de fluxo de capitais gerados pelas importações e exportações que dinamizam a economia nacional, fluxos imigratórios, mas, sim, pela crescente problematização social sobre os mercados ilegais e transnacionais, em especial, o tráfico de drogas e armas.

Porém, o mercado ilegal de drogas ilícitas e o desdobramento em violência urbana, ocasionada por este tipo de atividade vêm mobilizando especialistas interessados, nas últimas décadas no Brasil.

Cabe ressaltar, que os eventos relacionados a estes crimes e ocorridos nas cidades do Rio de Janeiro e São Paulo são mais repercutidas, dentre outros fatores pela proximidade com a "nominada grande mídia". As dinâmicas e reorganização do tráfico de drogas também são mais estudados nas grandes cidades no Brasil, como se percebe a partir do grande volume bibliográfico produzidos nesses locais (ZALUAR, 2009; MISSE, 1997 entre outros).

No entanto, o lastro empresarial do comércio de drogas ilícitas, inserido na dinâmica da expansão das facções criminosas, com predominância do Primeiro Comando da Capital (PCC) para outras regiões do país e, em especial, as localidades fronteiriças, indicam que gradativamente ocorre a transnacionalização das operações comerciais das facções criminosas. Então, pode-se dizer que os mercados ilegais não se restringem apenas aos grandes 
centros urbanos, pois é um fenômeno de ordem nacional, que vem ganhando maiores atenções dos órgãos de segurança pública.

Dessa forma, nesse artigo buscamos compreender a estruturação e as dinâmicas do trafico de drogas ( Pasta base e cocaína) na fronteira Brasil/ Bolívia e as implicações dessa atividade na localidade.

\section{Estados /cidades fronteiriças Corumbá/}

Corumbá, cidade situada na fronteira oeste do estado de Mato grosso do Sul, faz parte da conurbação com Ladário/Brasil, e Puerto Quijarro-Puerto Suarez/Bolívia. A área territorial corresponde a maior bacia alagada do mundo, concentrada na região do Pantanal, com mais de 64.962,720 de quilômetros de extensão e apenas pequena parcela territorial equivale à parte habitada, com população estimada em 109.294, aproximadamente (IBGE 2016). A principal rota de acesso à cidade fronteiriça e, da mesma forma ao resto do país se dá pela BR-262, e localizada a 450 quilômetros de distância da capital Campo Grande, MS.

A economia de Corumbá é voltada para o setor da mineração, agropecuária, turismo, e pelo setor comercial, como também para o setor de transporte de cargas. Este último setor merece destaque e vem crescendo desde a década de 1980, a partir dos investimentos do banco mundial na Bolívia (MACHADO, 2008).

Porém, a fronteira, do ponto de análise macrossociológica como um recurso econômico e social (OLIVEIRA, 2012) e torna-se um poderoso instrumento modelador da vida cotidiana fronteiriça, forjando a partir de novas dinâmicas, incluindo neste aspecto, a possibilidade de diversos rearranjos das sociabilidades locais (VALCUEND E CARDIA 2009).Para Oliveira (2009), os contatos sociais entre os diferentes níveis locais fronteiriços obedecem uma lógica, em diferentes níveis de funcionalidades, para o autor:

[...] são formas de integração funcional: o comércio da pequena produção industrial, o serviço de qualquer natureza, sem aporte formal, e outros que consolidam a 
complementaridade cotidiana, como a compra de imóveis, pequenas transações de capitais, o aluguel de máquinas, instrumentos e equipamentos ocorrido, em especial, no setor rural, entre outros. Em outros termos, um movimento de trocas que não se confunde com a ilicitude do contrabando (OLIVEIRA, 2009: 7-8).

O autor nos ensina que a vida cotidiana nas regiões fronteiriças é marcada por diversos sentidos, econômicos e nas sociabilidades locais. Essas relações hora de aproximação hora de afastamento, fazem parte das dinâmicas sociais fronteiriças.

Dessa maneira trabalharemos a fronteira como recurso econômico, social a partir dos atores sociais em nível local. Dessa forma entendemos a fronteira a partir de suas peculiaridades, onde os acordos tácitos estabelecidos historicamente na vida fronteiriça tomam forma ${ }^{2}$.

Neste sentido, Dorfman (2008) discute o contrabando em Santana do Livramento/Brasil eRivera/Uruguai, que segundo a autora, o ato de ir e vir de um lado para o outro da fronteira para compra e venda de produtos, não é considerado contrabando, esse termo é até alheio ao local. A compra de produtos obedece a lógica dos diferentes câmbios locais Neste sentido, não há julgamento moral por partes dos moradores locais "Os moradores da(s) cidade(s) levam tanto pesos como reais na carteira, para não se sujeitarem a câmbios desfavoráveis, eventualmente praticados nos estabelecimentos comerciais (DORFMAN, 2007: 89).

Para a autora contrabando de ocasião praticado rotineiramente na localidade faz girar a economia informal da localidade, aos quais são os produtos transportados de um lado para o outro da fronteira, criando assim uma rede de trabalhadores transnacionais que vivem dessa atividade na localidade. BentancorBosés (2008) demonstra nessa mesma localidade, além do benefício econômico, estão presentes também as interações sociais decorridas de

\footnotetext{
${ }^{2}$ Neste ponto é importante frisar que o dogma da soberania estatal (acordos internacionais e a imposição dos limites regulatórios da linha divisória) faz-se presente na vida fronteiriça seja através das forças de segurança, de defesa ou de outras instituições.
} 
matrimônios binacionais, o constante aprendizado dos idiomas português e espanhol entre os habitantes daquela fronteira.

Nas localidades de Assis Brasil (Brasil), Iñapari (Peru) e San Pedro de Bolpebra (Bolívia), situadas na tríplice fronteira da Amazônia Ocidental, Valcuende, (2009) traça uma importante contribuição para os estudos de fronteira ao analisar as funcionalidades entre essas três localidades, cada lado de fronteira oferece algo de relevante (preços e variedades de diversos produtos), como também na área da integração dos transportes públicos, laços matrimoniais e amizade, tudo isso contribui para as articulações informais transfronteiriças daquela localidade, evidenciando as estratégias sociais corriqueiras de sobrevivênciaque fazem parte na vida social dessas pessoas "3.

Percebe-se a existência, em vários momentos, de tensão entre a lógica do Estado e a lógica dos moradores que desafiam e transgridam as normas a medida articulam contados transfronteiriços a partir de diferentes interesses, produzindo dinâmicas econômicas, sociais e políticas singulares a localidade.

Um aspecto importante dos negócios fronteiriços é a possibilidade real de estabelecimento de negócios ilegais específicos, que lidam diretamente com a existência das fronteiras nacionais o que Oliveira (2005) chama de participação invisível:

Entretanto, devemos considerar que a riqueza da funcionalidade traz consigo uma série de outras atividades não apenas funcionais, mas também não lícitas - aqui chamada de participação invisível da funcionalidade. [...] As facilidades induzidas pela dinâmica das articulações econômicas sem escopo jurídico "abrem espaço" para penetração e consolidação de atividades nocivas (narcotráfico, contrabando, etc.) por grupos que se articulam em redes transnacionais" (OLIVEIRA, 2005: 7-8).

\footnotetext{
${ }^{3}$ Este processo de circulação de riquezas, de possibilidades de negócios e de acumulação de capital depende, portanto, de um espaço relativamente integrado em redes mais amplas (com outros centros urbanos), em circuitos do grande capital e com alguma infraestrutura de serviços do Estado. Neste sentido, as cidades de Corumbá-Ladário (Brasil) podem ser consideradas como um dos principais núcleos urbanos de fronteira entre o Brasil e seus países vizinhos, como um ponto de conexão entre portos do oceano Pacífico e Atlântico e que conta com rodovias, ferrovias, hidrovia e aeroportos.
} 
Este lado "obscuro" da funcionalidade está ligado ao recurso econômico e social da fronteira. As redes ilegais ${ }^{4}$ são geradas em certa medida a partir dos contatos cotidianos. Machado (2008) aponta para a primazia dessas redes que está justamente no conhecimento do território e, portanto em suas funcionalidades, facilidades (OLIVEIRA, 2005) e temporalidades ${ }^{5}$ fronteiriças (RABOSSI, 2002)

De acordo com (Machado, 1996) a transnacionalidade dessas redes, são fundamentais para o funcionamento desses negócios, ou seja, através da participação invisível na fronteira são acionadas as "competências circulatórias" (TELLES, 2009) nos quais os mais variados atores sociais transnacionais se arriscam, driblando o aparato estatal, levando e trazendo mercadorias e dessa forma movimentando toda uma rede cuja porosidade foge à magnitude da real estimativa de pessoas envolvidas nessas atividades ilegais (o tráfico de drogas, de armas, de pessoas e o contrabando seja ele "formiguinha" entre outros).

Na cidade de Corumbá, nota-se que o mercado local de venda de drogas ilícitas tanto no atacado quanto no varejo, se constituiu historicamente a partir das relações informais entre esses atores sociais transfronteiriços da região, aos quais observaram nessa atividade tanto uma possibilidade de se ascender socialmente devido ao lucro rápido da venda, quanto para as necessidades de subsistência em função da falta de oportunidades no mercado formal de trabalho na região ou mesmo por associações com facções criminosas(mais recentemente).

Hoje esse mercado ilegal está consolidado na região, primeiramente pelo número de bocas de fumo no varejo da cidade de Corumbá, que segundo a polícia civil passa de 280 pontos e em segundo lugar pelo crescimento da atuação dos comandos criminais brasileiros na região, principalmente a facção

\footnotetext{
${ }^{4}$ Para Machado ( 1998, p. 45) "[...]utilização das redes como instrumento heurístico se deve à representação da ação à distância, que se associa, assim, à extensão territorial. Nessa representação, o território não é um elemento neutro, e sua condição material não deve ser oposta à presumida condição imaterial da ação a distancia.

${ }^{5}$ As temporalidades é aqui entendida a na ótica da fiscalização da fronteira ao qual pode variar em vários momentos em um dia. Neste ponto também há de se pontuar os espaços de fiscalização que podemos dividir em permanentes e sazonais.
} 
Primeiro Comando da Capital(PCC), em conjunto com outras células criminosas bolivianas como por exemplo o Clã Dorado (FLCN, 2014).

O bazar corumbaense - Análise sociológica das relações sociais que se estabelecem a partir do comércio de drogas

Pensemos nos grandes centros urbanos onde circulam os produtos de preços populares, não tão longe, em qualquer cidade se vê uma barraca de algum ambulante vendendo um produto de "procedência duvidosa", vinda de algum ponto do globo por vias legais ou por contrabando até chegar a sua barraca e por fim ao consumidor. Esse consumidor é o que menos sabe da procedência da mercadoria e o emaranhado de pessoas e de circunstâncias operadas desde seu local de fabricação, passando por diversos circuitos sempre variando entre o legal e o ilegal. São esses circuitos transnacionais que alimentam a expansão da economia popular hoje em qualquer cidade brasileira (TELLES, 2009).

“A cidade como um bazar" (RUGGIERO E SOUTH, 1997) nome dado por esses autores ao analisar as cidades ocidentais dos países desenvolvidos, como um mercado com feições orientais onde as fronteiras entre o legal e o ilegal se entrelaçam através do trabalho precário, segundo Ruggiero e South:

Ao descrever o uso de drogas e os crimes relacionados às
drogas nas cidades contemporâneas, [...] a noção da cidade
como um "mercado" (market-place) e mais precisamente
como um "Bazar" por sua multiplicidade, barganha,
comércio e manobras incessantes. Neste "Bazar", a
legalidade e ilegalidade se misturam e as fronteiras morais
são constantemente negociadas
SOUTH,1997: 54).
(RUGGIERO E

As atividades realizadas no mercado irregular são tratadas pelos autores como "trabalho". Para esses autores a precarização do trabalho formal, o desemprego a expansão do mercado informal e das subcontratações, provocaram modificações diversas no modo de agir dos trabalhadores urbanos. A respeito Telles e Hirata (2017: 175) pontuam que “[...] o bazar metropolitano

\footnotetext{
${ }^{6}$ Texto traduzido pelo autor.
} 
- em perspectiva e como plano de referência para situar o tráfico de drogas em suas interações com as dinâmicas urbanas modernas".

Ainda de acordo com Telles e Hirata:

É justamente nesse ponto que as atividades ilícitas - e não só o tráfico de drogas - passam a interagir com as dinâmicas urbanas e compor o bazar metropolitano nos pontos de intersecção com os igualmente expansivos mercados irregulares, esse terreno incerto em que operam as "mobilidades laterais" de trabalhadores que transitam nas fronteiras borradas entre o trabalho, expedientes de sobrevivência e o ilícito. E também entre a rua e a prisão.(TELLES E HIRATA, 2017: 174)

Nesse sentido, Telles entende que as mudanças sociais, o aumento da violência e as transformações no "mundo do trabalho", contribuíram para aumentar o número pessoas que nada tinham a ver com os negócios do crime, mas que ingressaram de forma passageira em atividades ilegais para aumentar sua renda familiar, como estratégias de sobrevivência cotidiana nas dobras do legal e do ilegal (TELLES, 2009). De acordo com Misse :

O que distinguiria um mercado "formal" de um mercado "informal" seria, em suma, a sua maior ou menor participação num conjunto de regulações estatais. No entanto, a lógica economia do mercado produz relações complexas (e muitas vezes contraditórias) com essas regulações legais.[...] a designação de um certo tipo de mercadoria depende do seu significado contextual para a ordem pública, para a reação moral da sociedade e por suas possíveis (ou imaginárias) afinidades com outras mercadorias e práticas criminalizadas(MISSE, 2002: 15).

Dessa maneira, observamos o aceite da população corumbaense com os bingos, a venda de CDs e DVDs piratas, de celulares piratas e umas dezenas de quinquilharias vindas em sua maioria da Bolívia, vendidas na calçada do centro comercial de Corumbá, sem contar no pequeno camelódromo instalado há vários anos no terminal de ônibus antigo da cidade, onde seus ambulantes têm o aval da prefeitura para venderem seus produtos(piratas) devido ao pagamento de imposto. Neste local circulam, ainda, dezenas de pessoas vendendo e comprando vales transportes, sem contar os outros inúmeros pontos de vendas, 
espalhados pela cidade, de produtos contrabandeados, movimentando um mercado de compra e venda significativo.

Corumbá como os outros centros urbanos brasileiros ou como a maior parte das cidades brasileiras (ou todas) não ficou alheio a essas transformações do trabalho descritas acima. A taxa de aproximadamente $40 \%$ de pessoas na faixa da pobreza (IBGE 2010) está estampada no grande número de trabalhadores informais na cidade, multiplicando-se os negócios feitos a partir do espaço da casa, calçada e rua ou fazendo corres para uma boca, contrabandeando bebidas, estimulantes sexuais, perfumes, roupas, entre outros produtos ou atuando como mulas(para algum atacadista ou boqueiro) em direção à Campo Grande.

Dessa forma, a fronteira é entendida como recurso econômico e social, viabilizando uma série de arranjos sociais dinamizando a vida fronteiriça. Contatos gerados por atores transnacionais efetivados no convívio cotidiano. A viabilização e o sucesso das redes ilegais estão ligadas a estas relações.

Nesse sentido, trabalharemos com a ideia de um "bazar corumbaense" com todos esses elementos citados e o fato de a cidade de Corumbá estar situada em uma região de fronteira proporcionando (re)arranjos próprios nas dobras do legal/ilegal, licito/ilícito.

Nota-se que a consolidação desse mercado local de venda de drogas ilícitas tanto no atacado quanto no varejo, se deu a partir das relações informais entre esses atores sociais transfronteiriços (OLIVEIRA, 2013). Devido a integração funcional (OLIVEIRA, 2009), foram criadas relações das mais diversas entre bolivianos e brasileiros, aos quais viram nesse comércio ilícito a possibilidade de ascender socialmente devido ao lucro rápido da venda, quanto para as necessidades de subsistência em função da falta de oportunidades no mercado formal de trabalho na região. A estrutura atual no varejo foi formada entre as décadas de 1960 e 1970 a partir de núcleos familiares independentes não havendo barões do tráfico como em outras cidades do estado de Mato Grosso do Sul como Ponta Porã e Coronel Sapucaia (OLIVEIRA 2013, DINIZ, 2014). 
É preciso destacar algumas peculiaridades da economia criminal, que segundo Nordstrom (2007) tem a "confiança no coração de suas atividades". De acordo com esta autora, é justamente o fato de não haver a mediação de leis e de regulações do direito formal nas atividades criminosas, que abre espaço para relações extremamente personalizadas, que vão engendrar a coesão dos atores sociais envolvidos.

Sendo assim, categorias nativas de "comerciantes" de drogas como "confiança", em Nordstrom (2007) e "respeito", em Bourgois (2010) indicam que há toda uma rede de confiança que se estabelece entre os produtores, comerciantes e usuários de drogas, que de acordo com Nordstrom (Idem) caracterizariam a existência de um "código de ética", mediado diretamente nas relações face a face e que demandam a satisfação dos clientes, o pagamento das dívidas e o recebimento dos produtos, sob ameaça sempre latente do uso da violência para solucionar os conflitos. Peraldi (2007) nos mostra que:

[...] atividades que visam à produção, circulação, a comercialização de produtos proibidos de um ponto de vista moral ou legal, de atividades, nas quais a organização e a efetivação incorporam uma parte de violência física realmente exercida ou potencialmente presente na própria organização do ciclo produtivo, e enfim, de atividades realizadas por indivíduos, grupos marginais ou desviantes nas condições de total ou relativa clandestinidade $^{7}$ (PERALDI, 2007,111).

Nesse sentido que substituo o termotraficante (visão do Estado), pelo concepção do de comerciante (ponto de vista nativo). O boqueiro sabe que é visto como traficante pelas pessoas que os circundam, mas devido à consciência de sua atividade, gerando renda não só para sua família, mas também para outras, dinamizando o comércio local, esses indivíduos se percebem como comerciantes sagazes gerenciando seu comércio, a ponto de se tornar uma "empresa familiar", pois caso seja preso, deixará esse comércio-empresa para sua mulher e filhos, caso eles optem reabrir o ponto de venda (boca). Neste ponto é importante observar a dilaceração familiar, já que devido às batidas

\footnotetext{
${ }^{7}$ Tradução do autor.
} 
policiais, a rotatividade dos familiares presos pela polícia, o "entra e sai" do presídio é constante fazendo parte da rotina familiar (OLIVEIRA, 2013).

Este processo de circulação de riquezas geradas não só pelo comércio de drogas ilícitas, mas também pelo contrabando formiga ${ }^{8}$ dinamiza o comércio formal/informal dessa região de fronteira, esse dinheiro lavado em pequenos e grandes depósitos bancários (MACHADO, 1995), na padaria da esquina, no salão de beleza da vizinha, na marmitaria do bairro. Caráter difuso da economia que funciona como um sistema de regulação e de divisão desigual -"todo mundo toca um pouco nos benefícios do comercio" - possibilidade de promoção para numerosos atores sociais, implicados no comércio informal (criminosos ou não) - "homens de negócio" -(PERALDI, 20007), investem capital na fronteira "fazer a mágica" - mesma lógica e caminhos do capitalismo internacional.

Neste sentido, a ideia de um "bazar corumbaense" com todos esses elementos citados e com mais um elemento, fato de a cidade de Corumbá estar situada em uma região de fronteira proporcionando arranjos próprios nessas relações entre o legal/ilegal, articulando historicamente a formação do varejo local a partir de núcleos familiares aos quais ao logo dos anos desenvolveram dinâmicas próprias para a venda de drogas na localidade.

Mutações da casa de família no espaço urbano da cidade de Corumbá-MS: A boca familiar

Nos últimos anos, na cidade de Corumbá, foi possível perceber um processo de mudanças no espaço da casa e de vizinhança, devido às grandes mutações do trabalho na região, principalmente a partir da falta de oportunidades e de geração dos chamados empregos "formais". O espaço da casa adquire, a cada dia, as características de um "camaleão" frente às dificuldades cotidianas geradas pela falta de trabalho e de emprego bem remunerado nessa região. Dessa maneira, os moradores da cidade se veem

\footnotetext{
${ }^{8}$ É a prática utilizada de forma individualizada ou em grupos que utilizam-se da estratégia de transporte de pequenas quantidades de mercadorias de um lado para o outro da fronteira para driblar a fiscalização.
} 
obrigados a lançar mão do que podem para aumentar sua renda familiar, transformando suas próprias casas em um pequeno negócio. Utilizam-se, dessa forma, das possibilidades que a condição de morar na fronteira oferece, ou seja, o chamado "diferencial fronteiriço".

Em Corumbá é possível comprar os mais diversos produtos, dependendo do comércio que a pessoa se propõe a fazer na sua casa: desde roupas, celulares, bebidas alcoólicas, refrigerantes, materiais importados para serem usados em salão de beleza (secadores de cabelo, chapinhas), produtos de beleza (cremes, xampus), ou mantimentos como arroz, trigo, açúcar, óleo, e até mesmo carne de gado que sai muito mais barata em um açougue na Bolívia, do que em um açougue no Brasil. Um bom exemplo de utilização das vantagens econômicas de viver na fronteira são as feiras de rua, ou feirinhas "bolivianas" que acontecem em todos os dias da semana e em vários pontos de Corumbá e Ladário. Essas feiras abastecem, com seus produtos, grande parte das moradias dessas respectivas cidades. Além do próprio comércio dos ambulantes nas calçadas do centro de Corumbá, onde são comercializados celulares, CDs e DVDs piratas (COSTA 2010). Ou seja, qualquer pessoa que resida na fronteira poderá (in) diretamente fazer uso desse diferencial em seu cotidiano, dependendo de sua "perspicácia" em querer montar ou não um negócio. A fronteira representa, portanto, um recurso econômico e social.

A partir da metamorfose da casa, ora ambiente familiar, ora extensão de um negócio, percebe-se toda uma dinâmica de sobrevivência cotidiana familiar que condiciona a criação de grandes redes de sociabilidades (negócios, amizades, lazer) nos bairros onde "tudo mundo" conhece "todo mundo". Esta proximidade face a face é uma característica fundamental para os negócios pontuais feitos na vizinhança, sobretudo em relação ao crédito e confiança. Se uma pessoa deve a uma ou mais pessoas que fazem parte dessas redes, certamente seu crédito logo será negado em outros locais, até que a dívida seja sanada; ou se a pessoa for um "bom pagador", certamente não terá dificuldades, se precisar eventualmente comprar "fiado" nessas redes de relações. 
Dessa forma, observamos que ainda permanecem as formas de relações primárias nessas redes de sociabilidades do bairro (PARK, 1979) que são aprimoradas nas horas de lazer, em um passeio na praça, nos campeonatos de futebol organizados pelos próprios moradores da região, realizado no campinho ou quadra de futebol na praça do bairro, de acordo com Lauwe: “A evolução dos grupos locais sublinha a necessidade de encontrar novas realizações correspondentes às necessidades que se transformam constantemente." (LAUWE, 1979, p. 126) Assim, o bairro vai se socializando e agregando novos valores e formas estruturais, surgindo diversas histórias que ficam no "folclore" do bairro, que são contadas e recontadas pelos mais antigos, histórias essas tristes ou felizes que se moldam com o passar do tempo, onde surgem novas histórias seguindo as mudanças da vizinhança no decorrer dos anos. Dessa maneira, cria-se um equilíbrio nas relações do bairro, devido à própria dificuldade da vida na cidade, que aproximam os indivíduos do bairro como também os distanciam.

É de suma importância ressaltar que, neste espaço difuso entre a casa e a rua, nessa dinâmica da casa como uma extensão de um provável negócio, é que se baseia o trabalho do pequeno traficante de drogas dessa região de fronteira. Ou seja, a casa se torna um ambiente metamorfoseado em várias situações diárias, ora um ambiente familiar, ora uma extensão de um negócio (salão de beleza, bar) que pode funcionar como fachada para as rendas auferidas com avenda de drogas, servindo como uma "camuflagem" para uma eventual batida policial.

Dessa forma, o pequeno comerciante de drogas ilícitas se aproveita dessa rede de sociabilidade, construída a partir de um negócio lícito qualquer montado em sua casa, para vender a mercadoria ilícita. Essas redes de sociabilidades que circundam seu negócio lícito são de suma importância para o pequeno comerciante de drogas (boqueiro), devido ao grande número de amizades que são feitas por todo o bairro, criando uma condição propícia para a venda da drogas que garantirá sua "invisibilidade" já que devido às amizades feitas, dificilmente o boqueiro será denunciado pelos seus vizinhos: 
"Proximidade e contato entre vizinhos são as bases para a mais simples e elementar forma de associação com que lidamos na organização citadina"(PARK, 1979, p. 34). O fato é que a formação histórica e a proximidade da vizinhança influenciam na manutenção por muitos anos de uma boca em um bairro qualquer de Corumbá. Anteriormente chamei a atenção em relação às bocas famosas, que são um exemplo de sociabilidade de um ponto de venda de drogas ilícitas dentro de um bairro, alguns desses indivíduos donos dessas bocas atualmente encontram-se presos. Pensando nisso eu indago aqui a seguinte questão; Como pode uma boca ficar na ativa por mais de uma década, e seu dono e boca ficarem "famosos" nessa região de fronteira? Por que, em geral esse(s) dono(s) só são presos depois de uma operação da polícia, onde os agentes são "importados" de outras cidades para "estourar" a boca de fumo? Voltaremos nesse questionamento mais à frente, por hora me deterei nas informações que circulam nas redes de sociabilidade de vizinhança.

É preciso destacar que informações das mais diversas circulam nessas redes, desde uma conversa de boteco até o salão de beleza, que colocam em evidência todos os benefícios (alguma ação social realizada pelos governantes na localidade) e os malefícios (o próprio descaso dos governantes em relação aos serviços públicos básicos fornecidos na localidade, principalmente com relação à segurança). Manter a paz no local é, portanto, uma das preocupações dos boqueiros, pois caso furtos ou violência comece a aumentar no bairro, começarão a surgir os comentários em relação à boca, ao aumento de furtos, à sensação de insegurança causada pelos pipeiros ${ }^{9}$ que são os primeiros a serem culpados pelos eventuais furtos e roubos no bairro.

Por isso é importante ressaltar que esses comerciantes são exímios "mutantes" ou "camaleões" face aos perigos que eles têm que contornar nas dobras do legal e do ilegal, ora um pacato pai ou mãe de família, ora um (a) dono (a) de bar ou salão de beleza qualquer ou outro um negócio lícito, outra hora um traficante (visão do estado). De acordo com Telles "O fato é que as

\footnotetext{
${ }^{9}$ Usuários de pasta base.
} 
relações incertas entre o lícito, o ilegal e o ilícito constituem um fenômeno transversal na experiência contemporânea" (TELLES, 2009, p.156).

Entender as modalidades de trabalho "ilegal" implica, portanto, em um afastamento de pré-julgamentos que inserem este fenômeno apenas nas esferas judicial e criminal. Esses, os atores sociais envolvidos na economia "ilegal" não vêem a si mesmos como criminosos, mas como trabalhadores, "que fazem seu ganho", como empreendedores, inseridos na economia urbana da cidade de Corumbá $^{10}$. (PERALDI, 2010; TELLES, 2009). A atuação subterrânea desses indivíduos, mesmo que de conhecimento tácito por parte de conhecidos, parentes, ou da população em geral, também não impede o crédito "na praça", sua aceitação em lojas, em eventos sociais e estabelecimentos comerciais, muito pelo contrário. Ou seja, não é apenas o capital propriamente dito que se constrói a partir de trabalhos "ilegais", mas também o prestígio social e a garantia de circulação social em Corumbá e nas cidades vizinhas (OLIVEIRA E COSTA, 2012).

É na vida das ruas da cidade de Corumbá que podemos enxergar as relações sociais envolvidas nessas modalidades de trabalho e a capilaridade deste fenômeno na vida da cidade. Para termos a medida real do lugar que ocupam essas economias "criminais" na economia urbana desta fronteira, além das formas complexas de sua imbricação na economia dita "formal" e "legal", devemos estar atentos às formas difusas e mutantes em que essas modalidades de trabalho se apresentam no cotidiano, com grande extensão e multiplicação de atores sociais que usam o "diferencial fronteiriço" como um recurso.

Dessa forma, as pesquisas apontam até o momento, que se trata de um comércio de drogas específico nas bocas da cidade de Corumbá, com características distintas dos grandes centros do Brasil, cuja dinâmica obedece a critérios de vizinhança e parentesco, preferindo a invisibilidade de seus pontos de venda. Além disso, percebe-se que prevalece a negociação, envolvida nessas relações face a face, em vez do uso da violência, sobretudo no que diz respeito

\footnotetext{
${ }^{10}$ Essas pessoas ao terem algum ganho com a prática ilícita, logo investem seu ganho em algum tipo de negócio, juridicamente essa pratica é conhecida como lavagem de dinheiro, mas nesses circuitos ilegais utilizam-se o termo "Aprimorar a técnica".
} 
aos possíveis assassinatos por dívida ou disputas armadas por pontos de venda de drogas, que de fato são raros em Corumbá.

A boca familiar foi a estrutura mais importante que identificamos, tanto no atacado (banca) quanto no varejo, e o caráter familiar do negócio dentro do cotidiano da cidade torna-se de grande relevância devido às relações sociais que se estabelecem.

Há de se destacar os estudos de Misse (1998) que analisa a formação e a organização da boca de fumo tradicional, organizada através de parentescos e "aliança" com a vizinhança local na década de 1950 e 1960. Naquele momento os donos dos morros ainda eram "adorados" pela população local, ganhando até estereótipos de "Robin Hood" o "bandido social", era muito comum na visão das pessoas naquele período. Só a partir do incremento do consumo (causado pela entrada maior de consumidores de classe média - jovens em sua maioria), oferta de maconha e o aumento da distribuição de cocaína já no início da década de 1970, ocorrem transformações consideráveis na configuração deste comércio ilegal no Rio de Janeiro, como a organização em territórios e a formação das primeiras facções criminosas "Tudo isso ocorre muito antes que os presidiários da Ilha Grande, ex-assaltantes de bancos, comecem a organizar o que veio a se chamar de Comando Vermelho" (MISSE, 1998, p. 347).

É necessário ressaltar que existem várias dinâmicas do varejo de drogas, Grillo (2008) aponta para outra modalidade a partir de jovens traficantes de classe média carioca (chamado tráfico da pista). A autora estabelece diferenças importantes na construção desses circuitos em relação as estruturas estabelecidas nas favelas. Enquanto no primeiro caso o tráfico se constitui de forma pulverizada constituída a partir de redes de sociabilidade do traficante privilegiando a invisibilidade, no segundo caso, em comunidades de baixa renda, são altamente territorializados, hierarquizado, com emprego da violência constante e continuo (MISSE 1999, GRILLO, 2008).

Na cidade de Corumbá, ao longo dos anos, os loteamentos urbanos se concentraram nas mãos das imobiliárias, inflacionando os preços de casas e de terrenos no perímetro urbano da cidade, dessa maneira é comum existir mais de 
uma família vivendo em um mesmo terreno, mas em casas distintas. Em muitas dos pontos que visitei, existiam duas ou mais famílias nucleares vivendo em um mesmo terreno, mas em casas distintas. Muitas dessas casas são heranças deixadas pelos pais que ainda em vida cederam uma parte do terreno para que seus filhos construíssem.

Quando um familiar começa a vender a mercadoria ilícita, o jogo das relações familiares torna-se mais complexo:

\begin{abstract}
Após algum tempo frequentando a casa, na qual a fachada da boca era uma bicicletaria, observei que nesse local só morava uma família com seis pessoas, onde os filhos eram os que cuidavam da bicicletaria e das vendas de pasta base. Isto era perfeitamente normal para a família, consenso de todos, pois o pai trabalhava de moto-táxi autorizado e fazia disque entrega para eles próprios e para uma banca que se situava não tão distante de sua própria boca. A mãe trabalhava como empregada doméstica, mas estava desempregada e fazendo bico como diarista. Os moleques passavam o dia inteiro em frente de sua casa alternando os horários distintos da escola, um estudava pela manhã e o outro à tarde. Arrumando bicicleta, se divertindo, tomando tereré com os colegas e cuidando a polícia, já sabiam que seu pai estava sendo investigado como também a boca ou sua própria casa.(Diário de campo em 10 mai. 2012).
\end{abstract}

Esta reciprocidade e união familiar, apesar das divergências do caminho a ser escolhido por cada integrante da família, foram pontuadas por Feltran (2009) quando diz: "Até porque, esferas mais amplas da organização social e, sobretudo nos espaços públicos, a categorização que opõe "trabalhadores" e "bandidos" opera de modo muito distinto do que acontece[...] nos espaços privados" (FELTRAN, 2009: 22). Falta de emprego, doenças na família justificaram nesse ponto o apaziguamento dos conflitos familiares, como também a "aceitação" de "todos" em função do dinheiro ganho para as despesas de casa. Não quero minimizar a análise reduzindo-a a falta de emprego e por fim à necessidade de sobrevivência, pois em outros pontos que visitei, todos da família trabalhavam no setor formal de trabalho e mantinham umaboca em funcionamento. Dessa forma, as categorias de trabalhador e bandido ou trabalhador-bandido tomam forma e são pulverizadas nas relações cotidianas da cidade, monta-se uma bocae desfaz-se da boca com muita rapidez, isso é 
reforçado pelo depoimento abaixo relativo aos vários "tipos" de boca que existem na cidade:

Pesquisador: Existem variações de bocas?

Baixinho: Cara, existem vários tipos de boqueiros ${ }^{11}$, tem aquele que só vende de caixa e esse vai fornecer para aquele que vende de paradinha ${ }^{12}$. O boqueiro de bar, de casa e por ai vai, o que ele precisa? Ele precisa de alguém que forneça para ele,ele não tem como guardar de grande quantidade, então ele tem que comprar de picado e é nisso que ele vai comprar dessas pessoas que vendem de pouco, de uma caixa, de 100 a 150 gramas pelo baixo valor na hora da compra.

Tem aquele boqueiro que além de ser boqueiro ele atua de outra forma, então o que ele faz, na sua casa é uma boca, mas além disso, ele atua guardando a droga de outras pessoas, então ele ganha mais um pouco, só para se guardar, então para mim guardar eu já to ganhando e para ganhar mais um pouquinho eu vendo, entendeu! Então tem aquele cara que é boqueiro, mas ele guarda.

$\mathrm{E}$ tem aquele cara que não quer que as pessoas saibam que ele guarda então ele prefere fingir que ele é boqueiro, é como criar uma falsa imagem, então ele se passa como um boqueiro, mas quando chega 10 horas da noite ele não está mais vendendo, entende? O que é normal de todo mundo é virar a madrugada vendendo, então o que acontece, ele começa 6 da tarde e 9 horas da noite ele para! Porque, ele só queria chamar aquele tipo de atenção, - olha quem tá vendendo é aquele dali! Quando na verdade ele está guardando uma quantidade muito maior, e é essa quantidade que ele tá ganhando o dinheiro dele! Como que ele tá ganhando dinheiro? tá vendendo paradinha!

Ainda existem ainda aqueles que querem saber de quem ele compra, por mais que o comando interfira, mas ainda há a trairagem ${ }^{13}$ infelizmente, ainda tem muitos irmãozinhos aí que ainda trabalham desonestamente, vamos dizer assim, acaba passando a perna nos outros irmãos infelizmente. (BAIXINHO, 15 mai. 2012).

Outro ponto importante sobre a organização das bocas está logo no final da entrevista acima quando diz "por mais que o comando interfira" abre dois outros precedentes: a trairagem e as relações de lealdade entre as bocas independentes ${ }^{14}$ e o Primeiro Comando da Capital (PCC), processo iniciado a partir de 2006.

\footnotetext{
${ }^{11}$ Dono da Boca

${ }^{12}$ Pepelote com pequena quantidade de droga.

13 Traição.

${ }^{14}$ São pontos de venda de drogas onde seus chefes não são membros do PCC
} 
A entrada do "crime organizado" em Corumbá é recente e as relações de lealdade se fazem em um primeiro momento a partir do presídio, lugar onde aconteceram os primeiros batismos. Após os primeiros batismos ${ }^{15}$ a nova ética do crime vinda "de fora" da cidade e de dentro dos presídios é disseminada. Essa nova ética complexifica o comércio de drogas na região, subdividindo o varejo e o atacado de drogas ilícitas como também a própria criminalidade local. Hoje, se encontram no varejo local as bocas independentes, bocas que correm junto com o comando (que são comandadas pelos chamados irmãos ${ }^{16}$ ) e as bocas do comando. Os boqueiros independentes conhecem ou tem parentes como primos leais ${ }^{17}$ ou até mesmo irmãos do comando, assim são feitas essas relações de lealdade, passando pelas relações de parentesco e vizinhança como também através das relações de poder instituída pela ética do comando. A nova ética do crime local é que veio para acabar com a trairagem. É importante pontuar que apesar de haver o respeito à nova ética, o comando não interfere nos negócios dos independentes e nem dos irmãos, muito pelo contrário. $\mathrm{O}$ comando, segundo entrevista, atua como facilitador da entrada da droga nas bocas, como também compra o excedente de uma boca que não conseguiu vender toda a mercadoria, assim como também fornece a droga por consignação. Não é uma regra, mas os boqueiros que conheci preferem não contrair dívidas com o comando devido não só ao medo da dívida, mas principalmente pelo medo de perder sua independência frente aos seus negócios, até o pagamento da dívida.

Quando falamos nas bocas e mais propriamente as do comando, um ponto importante a ser destacado está justamente sobre o que seria exatamente uma boca do comando. Só porque o dono de uma boca é irmão do comando não significa que a boca seja do comando, "o que é da família é da família" quer dizer, os negócios do comando não podem se misturar com os negócios do

\footnotetext{
${ }^{15}$ Passagem de "primo leal" para "irmão"

${ }^{16}$ Membro "Batizado" no PCC.

${ }^{17}$ Individuo que não foi batizado mais corre junto com o comando.
} 
irmão fora da família, o irmão pode ter sua boca sem vínculo com a família ${ }^{18}$, mas eles executam as missões que derem em sua mão e todas as obrigações que o irmão tem com a família. As bocas do comando têm toda uma administração que fazem girar o dinheiro, além da droga vendida, como também o dinheiro das "missões" executadas pelos integrantes da família.

Essa distinção entre "corres" ${ }^{\text {"19 }}$ diferentes gera uma confusão para as pessoas que fazem "corres" eventuais e que buscam certo tipo de status no mundo do crime, pois essas pessoas sabendo que fulano é do comando e que ele faz correria para essas pessoas, logo diz para os outros que faz corres para o comando, o que não é verdade. $\mathrm{O}$ fato de um integrante do comando pedir para alguém fazer correria para ele não significa que estará fazendo corres para o PCC.

Outro ponto averiguado neste trabalho, logicamente foi observar as localizações e número de vendas, ou seja, se a localização influenciaria no número de vendas ou se apenas a qualidade do produto e confiança no boqueiro, devido ao movimento diário de vendas. Logicamente isso foi uma tentativa hipotética, porque seria impossível entrar em todas as bocas da cidade e observar as movimentações diárias, dessa forma analisaremos esta questão através da entrevista logo abaixo, que serviu para reforçar essa ideia insipiente, debatida a seguir:

Gordão: A movimentação depende da boca, tem boca que é semana inteira, em outras bocas a partir de quinta ${ }^{20}$ começa, varia de boca para boca, a localização interfere muito, tem boca que é perto da polícia, daí é embaçado chegar lá, tem outras que já é muito visado, quando você entra na rua todo mundo já sabe o que você vai fazer lá, essas bocas são de muito tempo vendendo, a polícia já estourou, já voltou novamente, estourou de novo e voltou a funcionar novamente.

Pesquisador: E na boca como que os caras gostam de vender?

\footnotetext{
${ }^{18}$ Mesmo que PCC.

${ }^{19}$ Forma de ganhar dinheiro.

${ }^{20}$ Pensando na entrevista acima, sem entrar no ônus monetário que a venda proporciona, o que me intrigou nessa fala foi justamente o início do movimento com o aumento do movimento nas bocas a partir da quinta-feira. Justamente a partir desse dia da semana na cidade de Corumbá começa um maior movimento noturno, devido aos eventos nos bares do centro da cidade e em casas de shows.
} 
Gordão: Os caras gostam de vender mais em paradinhas porque o lucro é maior. Quando os caras compram 200gramas, cada caixinha são 10 gramas, vai dar 20 caixinhas aí os caras misturam e fazem mais uma ou 2 caixinhas e cada caixinha dessas os caras vendem a 60 ou 70 conto. Se forem vender em paradinha, ganham mais que o dobro, tem paradinha de 5 de 10 conto. Aí tem cara que pega $1 / 4$ da caixa que sai 15 reais, mas quando muita gente vai usar daí o cara pede caixa. A base é a mesma coisa a caixa custa 60 conto só que a paradinha custa 1 real e o cara que usa base não tem como comprar uma caixa de base!(GORDÃO, 20 ago.2012)

É na movimentação que ocorre da boca que são feitos novos contatos e novos clientes que são geralmente apresentados por outros compradores que chegam ao local e rapidamente compram a mercadoria. Mesmo que seja um encontro rápido, esse momento é fundamental para a quebra do distanciamento entre o novo cliente em relação ao boqueiro, deixando a porta aberta para seu retorno, entrando no circuito de vendas do boqueiro.

- O boqueiro dificilmente vende para quem ele não conhece, isso funciona como precaução contra investigações policiais. Agora com relação à localização, faz sim diferença na venda, mas essa diferença é atenuada pelos corres de motos que são realizados a noite inteira. É lógico que uma boca perto da polícia será um ponto que terá menos movimentação noturna, justamente pelo flagrante que isso ocasiona. Outras regiões devido ao tempo da boca no que chamei de bocas famosas ${ }^{21}$ pelo tempo do negócio no local, acaba estigmatizando a vizinhança, como também eventuais pessoas que possam estar passando pelo local poderão ser automaticamente chamadas de "viciado" pela simples passagem pelo local, já que ele não pertence e não é conhecido na vizinhança.

A movimentação de venda dentro de uma boca movimentada ao que pude apurar não em contagem de paradinhas vendidas, mas sim por preço de papelote vendido, geralmente saem de $1 / 4$, o que significa que, para uma

\footnotetext{
${ }^{21}$ São pontos de venda de drogas que a décadas praticam esse crime. Por causa disso, esses pontos acabam sendo reconhecido pelo nome do boqueiro, por causa da rua em que se situa dentre outras formas de identificação.
} 
paradinha $^{22}$ de $1 / 4$, três pessoas vão usar, isto aponta também para o grande problema social que a cocaína e a pasta base estão gerando, a partir do número crescente de usuários devido ao seu baixo custo e sua facilidade em obtenção. Não queremos generalizar, pois não visitamos todos os pontos de venda de Corumbá, mas é um fato a se pensar.

Nesse processo de acumulação de capital no circuito ilegal de venda de drogas, o dinheiro logo é reinvestido na economia legal a partir de pequenos negócios montados, no próprio ponto de venda servindo como disfarce para possíveis incursões policiais.

\section{Estruturação das bocas - Há disputas por territórios?}

É sabido que nos grandes centros urbanos há a existência do poderio militar e bélico de facções criminosas. Poderio esse que ajuda a guardar o território político militar da facção e principalmente ajuda a garantir que a venda de drogas ocorra normalmente, havendo, dessa forma, toda uma estrutura de caráter militar com o fim de guarnecer o território contra as eventuais investidas de traficantes rivais, milícias e também contra a polícia. As disputas por territórios é um fato que causa pânico aos moradores de favelas quanto dos bairros que vivem em constante insegurança devido à violência.

Dessa maneira indago a seguinte questão: o que há de diferente nas territorialidades do tráfico de drogas em uma cidade fronteiriça como Corumbá que é frequentemente estigmatizada como um local "sem leis", o que se diferencia dos grandes centros urbanos brasileiros? Corumbá é uma cidade violenta? Se for violenta, é por causa do tráfico ou é por causa de sua condição de cidade fronteiriça que já traz a carga de estigmatização de ser um local violento para os habitantes que não residem nessas localidades? A partir do depoimento de Baixinho (um comerciante de drogas local) tentarei elucidar dois momentos distintos do tráfico de drogas em Corumbá e que atualmente observa-se um processo de mudanças.

${ }^{22}$ Papelote com drogas. 
Pesquisador: - Como é que se monta uma boca de fumo?

Baixinho: - é muito fácil, você consegue o produto e começa a vender [...] o espaço é para todos, por isso não existe conflitos em montar uma boca ao lado da outra. O espaço é para todos e quem determinou isso é o comando.

Pesquisador: Quando isso Baixinho?

Baixinho: é que antigamente acontecia de que, como o comando, quando a gente fala comando, a gente fala do comando vermelho e o primeiro comando da capital coligados [...] no estado, só que os dois têm seus próprios estatutos, ambos se respeitam.

Então o que acontecia antigamente, era a lei do mais forte, o que acontecia, se o cara fosse vender lá ele iria ter que comprar de mim, por que senão eu vou lá e vou tomar a boca dele! Antigamente era assim. Depois que entrou o comando teve aquela mega rebelião foi estabelecido que o espaço é para todos, todos tem o direito de trabalhar em qualquer lugar sem passar por cima dos outros. Se eu quero vender e já tem um que vende na área, pergunta-se se tem algum problema vender na área e logo se diz que não tem problema.

O que não pode é vender no preço abaixo da tabela que se tem é claro, se todo mundo está em uma tabela então é sempre ali. Na verdade você não pode vender acima da tabela na verdade, o que não se aceita é extorsão, você tentar extorquir o viciado, por que o viciado é o seu freguês, tem que dar valor a ele sim, ele sempre tem a razão e tem o direito dele. Então, é tal valor, e pra todo mundo, a quantidade é um valor pra todo mundo.

Pesquisador:- Mas e a questão de antigamente quando um boqueiro resolvia tomar a boca do outro? Isso era uma prática comum? Isso chamaria muita atenção da polícia?

Baixinho: A própria polícia que fazia isso! Porque quem era forte antigamente tinha a polícia do lado! Isso era comum, e é isso que vem se quebrando hoje em dia. Pra mim ser forte tem que ter alguém que me defenda não é? Quem vai me defender? É a polícia. Era a polícia que ia e estourava o local. Então o que acontecia antes da polícia ir estourar a boca, eu ia lá conversar com o cara (boqueiro) que estava comprando de um atacadista de outra região, eu ia lá conversar com ele [...] olha o negocio é assim, essa aqui é minha área e eu quero que você compre de mim pra você revender aqui a esse preço e você vai me pagar esse preço, você aceita? Se não aceitou, tudo bem! Aí ia lá e comunicava, - ó, o homem tá lá e sem acordo! Pronto estourou a boca dele! Fui conversar, não quis, então vai ser preso. Então antigamente era assim, depois a igualdade para todos, o espaço aberto para todos, para todo mundo poder trabalhar. Você compra de quem você acha que o produto está melhor ou aquele que você achar mais acessível pra você é desse que você vai comprar. (BAIXINHO 30 jul. 2012). 
Desde 2010, quando iniciei as pesquisas de campo nessa região de fronteira, procurei tentar entender o que diferenciava o comércio de drogas ilícitas dessa região de fronteira dos grandes centros brasileiros. $\mathrm{O}$ primeiro contraste observado foi a questão da violência que emana desse tipo de comércio. Nos grandes centros urbanos brasileiros, a violência crescente a partir da década de 1970, está associada em partes ao comércio de drogas ilícitas, como observado por muitos estudiosos do assunto, dentre eles, Misse (1997 e 2003), Zaluar (2009), Adorno e Salla (2007). Também é fato que a violência que esse tipo de comércio acarreta, depende de sua estruturação no varejo e as mudanças internas do mundo do crime que influenciam diretamente na violência nas cidades. Hirata (2010) observa isso, analisando a entrada do comando (PCC) nas periferias de São Paulo, onde logo impuseram como uma das principais regras, o não matar e introduziram o chamado debate ${ }^{23}$. Hirata também ressalta que esse novo comportamento a partir da ética "o proceder" (MARQUES, 2010) colocada pelo comando coincidiu com a diminuição de homicídios na cidade de São Paulo. Grillo (2008) também observa as relações de violência na estrutura do comércio de drogas nas classes médias do Rio de Janeiro, onde essas relações praticamente não existem. Dessa forma, drogas e violência nem sempre andam juntas. Segundo Misse:

Uma parte importante da explicação dessa associação do varejo do tráfico com a violência deve-se ao surgimento de quadrilhas que controlam territórios em áreas urbanas de baixa renda, o que leva a intermitentes conflitos com outras quadrilhas pelo controle desses territórios e de seus pontos de venda (MISSE, 2010: 20).

Complementando com Grillo (2008) que entende que a comparação das dinâmicas territorial e organizacional dessas redes fornece elementos importantes para a compreensão dos aspectos culturais de violência que se constrói em torno delas.

Portanto o uso ou não da violência está diretamente associado à formação estrutural das redes do comércio de drogas, dessa forma é importante

\footnotetext{
${ }^{23}$ Discussão e julgamento, espécie de "tribunal” com ritos e hierarquia social.
} 
observar as peculiaridades dos processos históricos da formação dessas redes, no varejo.

Após o incremento da demanda e a venda de maconha e cocaína no Rio de Janeiro inicia-se o processo de territorialização das bocas tradicionais, ocasionando uma verdadeira guerra de quadrilhas no Rio de Janeiro nos anos de 1970 por disputas de pontos de vendas antes mesmo da formação do comando vermelho.

O mais importante é que a partir de meados ou do final da década de 1960 e $1970^{24}$ (OLIVEIRA E COSTA, 2011; DINNIZ, 2014) é que aparentemente se encontra o início dessa estruturação. Estruturação essa organizada com base nas relações de vizinhança, parentesco e proximidade. Observando os depoimentos, percebi que a boca em si, não é passada para pessoas diferentes quando ela é estourada pela polícia, devido ao estouro, quem está na frente do negócio no momento é preso. Nesse momento o ponto pode (ou não) ser rearticulado com uma ou outra pessoa da família, que continuará o empreendimento familiar, ou seja, é um negócio familiar em que todos estão (na maioria dos casos que conheci) envolvidos de alguma forma nesse negócio. Dessa forma, a boca é passada de pai para filho, o que representa um empreendedorismo $^{25}$ local que com o decorrer do tempo foi se modificando devido ao aumento das batidas policiais, se entrelaçando em atividades legais, para escamotear os lucros auferidos pela atividade ilícita.

Corumbá, a partir dos anos 70 do século XX, entrou na rota das redes ilegais do tráfico de drogas, primeiramente apenas como uma "cidade corredor" ou ponto de conexão dos grandes cartéis da droga para o abastecimento dos grandes centros urbanos como Rio de Janeiro e São Paulo (OLIVEIRA E

\footnotetext{
${ }^{24}$ Observa-se também a história de três comerciantes (dois atacadistas e um boqueiro) que também atuavam como pistoleiros, que na década de 1980 comandavam uma parte considerável da distribuição de drogas nessa região. A história desses três foi contada por muitos desses comerciantes e também por pessoas que eram próximas deles, infelizmente devido a razões éticas da pesquisa, levando em consideração os familiares, já que alguns desses familiares permanecem no negócio até hoje na cidade (mas sem a mesma força de seus antecessores na da década de 1980) não poderei transcrever essa história.

${ }^{25}$ Esse empreendedorismo é chamado de "Pequenas empresas grandes negócios" em alusão ao antigo slogan do SEBRAE. São os reinvestimentos em "pequenos" negócios locais como um salão de beleza, loja de roupas, bar etc.
} 
COSTA, 2011). Devido à facilidade em adquirir o produto nessa região, ao longo do tempo, criou-se uma rede interna de distribuição da droga nessa região de fronteira. Hoje, nota-se a consolidação dessas redes devido ao grande número de pontos de venda de drogas na cidade. De acordo com Lauter da Silva Serra, então secretário de saúde de Corumbá, no debate do Encontro Estadual de combate às Drogas "Hoje em Corumbá existem mais de 280 bocas cadastradas, fora as que não estão ${ }^{26 "}$. O mais certo é que a partir de 2006 iniciase um processo de estruturação do varejo e atacado local, essa estruturação é acarretada pela entrada do Primeiro Comando da Capital (PCC) nas ruas de Corumbá a partir do ano referido, esta mudança se configura nas relações de poder entre os comerciantes/ilícitos como também com a polícia, e este processo pode ser observado em dois pontos da entrevista transcrita no início deste subitem.

Primeiramente notamos a lei do atacadista "a lei do mais forte", aquele que pagava a polícia para fechar a boca de outro, como forma de retaliação devido ao boqueiro não ter comprado a sua mercadoria, já que o próprio é que vendia para aquela região. Após a política de vizinhança ser acionada e essas mediações terem sido um fracasso, a polícia foi acionada como forma de manter e reforçar o poder local do atacadista e seu imbricamento com os meios legítimos de fiscalização do estado. Esta dinâmica ao que parece está em mudança desde 2006.

O segundo momento em que "Tem espaço para todos" ou "o espaço é para todos" (uma tônica aparentemente definida pelo Comando a partir de 2006) é uma das principais frases que escuto dos meus interlocutores, no atacado e no varejo. Essa dinâmica do "espaço para todos" é percebida se materializando na não violência entre os boqueiros locais. Isso não significa que não haja atritos, se sua boca tem menos movimentos que a outra, que se situa perto da sua é a "lei do mercado" o boqueiro terá certamente que agir, para que seu movimento retorne à normalidade sem atravessar o esquema do seu

\footnotetext{
${ }^{26}$ Seminário Estadual de Políticas Públicas de combate as drogas realizado na cidade de Corumbá/MS. 2 jul.2011.
} 
concorrente. Outro ponto importante é que ninguém quer colocar sua família em risco devido à alguma retaliação, então os negócios são pontuais e a concorrência aberta entre todos. Chamar a polícia para o fechamento de uma boca concorrente por outro boqueiro é hoje traição, podendo acarretar sérias sanções do meio.

Quanto ao que diz respeito ao possível tabelamento e metas de venda, isso diz respeito às bocas comandadas pelo PCC, já que tem que fazer girar dinheiro para a cadeia, diferentemente dos independentes, mas é fato que a tabela de "rua" é a que todos seguem já que há muito tempo a mesma está em vigor e isso faz com que, na maioria das bocas, existam paradinha (cocaína neste caso) de cinco reais, de 10 reais com a mesma quantidade em todas as bocas, (o que pode variar é a qualidade do produto).

Mesmo que existem diversas forças dentro do varejo e do atacado local (varejo, atacado independentes, os comandos - PCC e em menor força o Comando Vermelho e mais o atacado do lado boliviano da fronteira), há uma tendência não para as disputas, mas sim para as alianças.

\section{Considerações finais}

As transformações do trabalho notadas primeiramente por Ruggiero \& South (1996) colocam em voga uma nova perspectiva para os estudos sobre o trabalho e o trabalhador moderno, em que as "mobilidades laterais" resultantes das transversalidades que o trabalhador passa entre o lícito para o ilícito. Esses processos demonstram a própria mudança na postura da moral na realização de determinadas atividades.

Deste modo o "bazar corumbaense" ou sendo mais ousado, o "bazar fronteiriço" desta semi-conurbação que envolve Puerto Suarez-Puerto Quijarro/Bolívia e Corumbá-Ladário/Brasil, está envolto em cenário maior que é o fluxo de mercadorias internacionais que a cada dia aumenta devido ao corredor bioceânico. Toda essa riqueza desses fluxos internacionais que passam por essa região, contrasta com a realidade precária local. 
A peculiaridade deste comércio nesta região está justamente nas formas e meio em conseguir a droga. Enquanto a droga para chegar a um grande centro urbano torna-se necessário um emaranhando de trabalhadores e uma logística complexa, nesta região, os traficantes (visão do estado) conseguem a droga no país produtor, sem precisar de grandes "esforços". A expansão do mercado da cocaína no varejo local é fruto da facilidade em conseguir a droga como também da demanda crescente de usuários. Devido à proximidade com o país produtor e fornecedores, o produto chega com mais facilidade nas bocas como também se torna muito barato para a venda ao consumidor, isso é refletido nas variabilidades de preços existentes na "tabela de rua" e que dependendo da ocasião podem ser negociáveis.

As relações de vizinhança, parentesco e proximidade tão presentes na cidade de Corumbá, a lógica do empreendedor, as "pequenas empresas grandes negócios", são feições locais e que estão inseridas na própria gestão local do crime.

Por fim, apesar de o PCC se fazer presente na região desde 2006, há cordialidade e convivência entre duas lógicas, os independentes e o comando. "O espaço é para todos", explícito no discurso de "Paz, justiça, igualdade" vem se expandido e reestruturando as relações sociais já existentes dentro do "mundo do crime" fronteiriço.

\section{Referências}

ADORNO, S e SALLIA, F.Criminalidade organizada nas prisões e os ataques do PCC. Estudos Avançados 21 (61), 2007.

BOURGOIS, Felipe. En busca de respeto: vendendo crack em Harlem. $1^{\text {a }}$ ed. Buenos Aires: SigloVeintiuno Editores, 2010.

FELTRAN, Gabriel de Santis. Trabalhadores e bandidos: categorias de nomeação, significados políticos. Revista temáticas, ano 30, vol. 15, pp. 1150, 2007.

GRILLO, Caroline Christoph. O "Morro" e a "Pista": um estudo comparado de dinâmicas do comércio ilegal de drogas. Revista Dilemas N. 1, Vol. 1 (JUL/AGO/SET), 2008. 
HIRATA, Daniel Veloso. Sobreviver na adversidade: Entre o mercado e a vida. Tese de Doutorado apresentada ao Programa de Pós-Graduação em Sociologia da Faculdade de Filosofia, Letras e Ciências Humanas da Universidade de São Paulo, 2010.

INSTITUTO BRASILEIRO DE GEOGRAFIA E ESTATÍSTICA- IBGE. Disponível em: <http://www.ibge.gov.br/home/>. Acesso em: 08 jan.2013.

Machado, Lia O. Movimento de dinheiro e tráfico de drogas na Amazônia. Em M. M. Ribeiro e S. Seibel (coord.) 1995. Drogas. Hegemonia do Cinismo. S. Paulo: Memorial, p. 217-242.

MARQUES, Adalton. "Liderança", "proceder" e "igualdade": uma etnografia das relações políticas no Primeiro Comando da Capital. Etnográfica,junho,14 (2): 311-335, 2010.

MISSE, Michel. Malandros, marginais e vagabundos: A acumulação social da violência no Rio de Janeiro. Rio de Janeiro. Tese (Doutorado em Sociologia) - Instituto Universitário de Pesquisas do Rio de Janeiro, 1999.

Rio como um Bazar. A conversão da ilegalidade em mercadoria política. Insight Inteligência. Rio de Janeiro: v.3, n.5, p.12-16, 2012.

NORDSTROM, Carolyn. Global Outlaws. Crime, Money and Power in the contemporary world. Berkeley, Los Angeles and London: University of California, 2007.

OLIVEIRA, G. F. Nas bocas da cidade de Corumbá-MS; O comércio de drogas na fronteira Brasil/Bolívia. Dissertação. (Mestrado em Estudos Fronteiriços) - Fundação Universidade de mato Grosso do Sul. Corumbá, 2013.

OLIVEIRA, Tito, C. M.“A lógica espacial do território fronteiriço - os casos das aglomerações de Ponta Porã- Pedro Juan Caballero e Ládário- CorumbáPuerto Quijarro- Puerto Suarez. In: SEBRAE (Org).Mato Grosso do Sul sem fronteiras: características e interações territoriais. Campo Grande: SEBRAE, p. 239-255, 2010.

OLIVEIRA,G.F.; COSTA, G.V.L. Redes ilegais e Trabalho Ilícito: comércio de drogas na região de fronteira de Corumbá/Brasil - Puerto Quijarro/Bolívia. Boletim Gaúcho de geografia, no 38, n.1-2/ , p. 137-156, 2011.

. Esquemas de fronteira em Corumbá (MS): Negócios além do legal e do ilegal. DILEMAS: Revista de Estudos de Conflito e Controle Social - Vol. 7 - no 2 - ABR/MAI/JUN - pp. 207-232, 2014.

PERALDI, Michel. EconomiesCriminelleset Mondes dÁffaire à Tangier. Cultures e Conflits, No. 68, p. 111-125, 2017. 
RABOSSI, Fernando. Nas ruas de ciudaddel Este: vidas e vendas num mercado de fronteira. Tese -PPGA- Museu Nacional - UFRJ, 2004.

RUGGIERO, Vincenzo; SOUTH, Nigel. The Late-Modern City as a Bazaar: Drug Markets, Illegal Enterprise and the 'Barricades'. The British Journal of Sociology, vol.48, no.1 (mar. 1997), PP. 54-70, 1997.

TELLES, Vera da Silva. Ilegalismos urbanos e a cidade. Novos Estudos, Julho. P. 153-173, 2009.

Recebido em: 22 de abril de 2020 Aceito em: 27 de abril de 2021 